\title{
Material and geometric nonlinear analysis of reinforced concrete frames
}

\section{Análise não linear física e geométrica de pórticos de concreto armado}

\author{
E. PARENTE JR a \\ evandro@ufc.br \\ G. V. NOGUEIRA a \\ geovanneviana@gmail.com \\ M. MEIRELES NETO a \\ marcelomeirelesneto@gmail.com \\ S. MOREIRA a \\ leandrosmcivil@gmail.com
}

\begin{abstract}
The analysis of reinforced concrete structures until failure requires the consideration of geometric and material nonlinearities. However, nonlinear analysis is much more complex and costly than linear analysis. In order to obtain a computationally efficient approach to nonlinear analysis of reinforced concrete structures, this work presents the formulation of a nonlinear plane frame element. Geometric nonlinearity is considered using the co-rotational approach and material nonlinearity is included using appropriate constitutive relations for concrete and steel. The integration of stress resultants and tangent constitutive matrix is carried out by the automatic subdivision of the cross-section and the application of the Gauss quadrature in each subdivision. The formulation and computational implementation are validated using experimental results available in the literature. Excellent results were obtained.
\end{abstract}

Keywords: concrete structures, nonlinear analysis, plane frames, finite element method.

\section{Resumo}

A análise de estruturas de concreto armado até à ruína requer a consideração das não linearidades física e geométrica. Contudo, a análise não linear é mais complexa e possui custo computacional mais elevado que a análise linear. Com objetivo de obter uma alternativa eficiente para a análise não linear de estruturas reticuladas de concreto armado, este trabalho apresenta a formulação de um elemento finito de pórtico plano não linear. A não linearidade geométrica é tratada através do uso da formulação corrotacional e a não linearidade física é considerada através do uso de relações constitutivas apropriadas para o concreto e o aço. A integração dos esforços e da matriz constitutiva tangente é realizada pela subdivisão automática da seção transversal em faixas seguida pela uso da quadratura de Gauss em cada faixa. A formulação e implementação computacional são validadas através da comparação com resultados experimentais, tendo sido obtidos excelentes resultados..

Palavras-chave: estruturas de concreto, análise não linear, pórticos planos, método dos elementos finitos.

a Universidade Federal do Ceará, Fortaleza, CE, Brasil. 


\section{Introduction}

The structures of reinforced concrete buildings are constituted mainly of beams and columns rigidly connected, forming plane frames. The simulation of the behavior of these structures in a realistic way, especially near failure, requires the consideration of material nonlinearity, due to the presence of effects such as concrete cracking and reinforcement yielding, as well geometric nonlinearity, due to large displacements and high compressive forces. The search for more economical designs, the use of high strength materials and slender structures has increased the importance of nonlinear analysis. Concrete has a highly complex mechanical behavior. Thus, plane and solid elements with two and three dimensional constitutive models have been used in the computational modeling of lab tests. These constitutive models allow representing the effects of stress state on concrete behavior, leading to an excellent agreement of the numerical and experimental load-displacement curves [11]. However, this approach is not feasible for the analysis of building structures formed by a large number of members (columns and beams) due to the high computational cost, besides the difficulty of geometric modeling and mesh generation. On the other hand, the design of building structures is generally carried out using linear analysis and frame elements. The effect of nonlinearity is considered approximately using the secant modulus to represent the material nonlinearity and the parameter $\gamma_{z}$ to estimate the secondorder effects (geometric nonlinearity) [1].

In order to perform the nonlinear analysis of reinforced concrete reticulated structures simple and efficient way, this paper presents the formulation of a plane frame finite element for geometrical and material nonlinear analysis. The geometric nonlinearity is consid-

Figure 1 - Kinematics of the co-rotational element (Adapted from Battini (3))

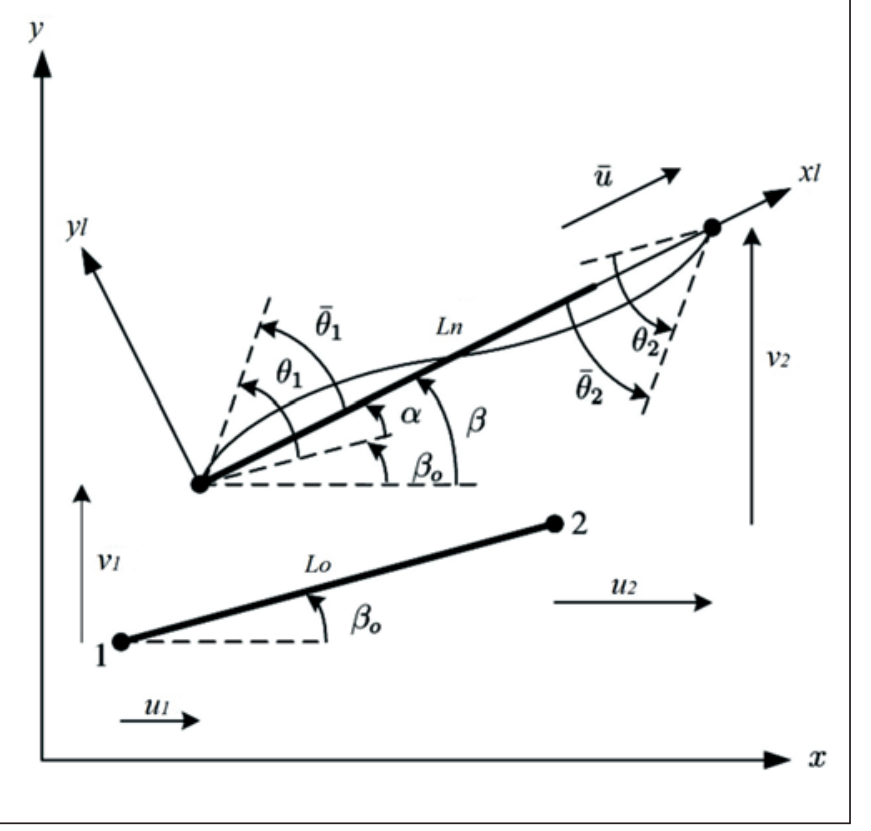

ered by using the co-rotational formulation, allowing the analysis of structures with large displacements and rotations.

The material nonlinearity is considered using nonlinear stressstrain relationships for steel and concrete in compression presented in standards NBR 6118:2007 [1] and Eurocode 2:2004 [7]. The contribution of the concrete in tension (tension stiffening) is considered using the CEB model [10]. A new method for the integration of stresses and the constitutive matrix over reinforced concrete cross-sections is proposed in this paper. This method is based on the automatic subdivision of the cross-section in accordance with the ranges of the stress-strain curves and the use of Gaussian quadrature for each segment, resulting in a simple, efficient and accurate formulation. Moreover, this method is independent of the stress-strain curve adopted.

The formulations and implementations are evaluated through comparison with experimental and numerical results available in the literature. This work presents an assessment of the influence of the finite element discretization and the number of points used for cross-section integration.

\section{Plane frame co-rotational finite element}

The equilibrium of a structure under external loading occurs when the internal forces generated by the deformation equilibrates the external forces applied. Therefore, the equilibrium must be written in the deformed configuration of the structure. When displacements are small, changes in geometry are negligible and the equilibrium can be written in the undeformed configuration. On the other hand, the geometric nonlinear analysis should be used when the displacements and rotations are large and the equilibrium needs to be written in the deformed configuration. The geometric nonlinear analysis can be performed using the Lagrangian or co-rotational formulations. The Lagrangian formulations [2] are more appropriate to continuous finite elements, once the use of the GreenLagrange strains allows filtering the rigid body displacements. However, the application of Lagrangian formulations in frame elements with large displacements and rotations lead to very complex expressions [13]. Thus, most of these elements are limited to the problem of moderate rotations [12][16]. An alternative approach to consideration of large displacements and rotations based on the use of Reissner's deformations was presented in [4]. However, this formulation is very complex, involving interpolation of membrane deformation and curvature along the element.

The co-rotational approach is based on the separation of rigid body displacements from element deformations by using a coordinate system that follows the element [3][6]. This approach was adopted in this work because it allows considering large displacements and rotations in a simple and computationally efficient way, while simplifying the consideration of material nonlinearity, as discussed in the following.

The Figure 1 shows a co-rotational plane frame element with rigid body and deformation displacements. In this figure, the coordinates of nodes 1 and 2 in the global system are given by $\left(x_{1}, y_{1}\right)$ and $\left(x_{2}, y_{2}\right)$, respectively. Figure 2 shows the degrees of freedom of the co-rotational element on the local system and the associated internal forces. This figure shows that there is no rigid body displacements in local system, but only three deformation modes for the plane frame element: one associated to the axial strain $(\bar{u})$ and two associated to flexural deformations $\left(\bar{\theta}_{1}, \bar{\theta}_{2}\right)$. 
Figure 2 - Degrees of freedom and internal forces of the local element

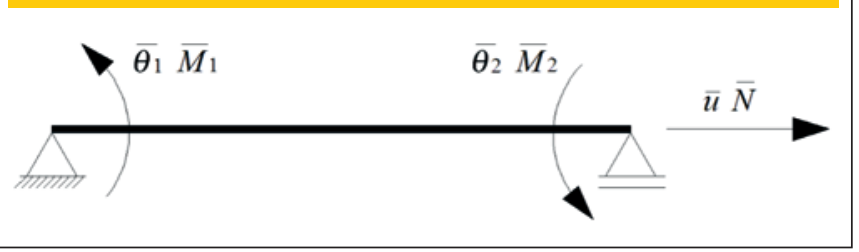

\subsection{Strains}

Based on the parameters of Figure 1 and the deformation modes of Figure 2, it is possible to define the displacements due to the deformation of the element as:

$$
\begin{aligned}
& \bar{u}=L_{n}-L_{0} \\
& \overline{\theta_{1}}=\theta_{1}-\alpha \\
& \overline{\theta_{2}}=\theta_{2}-\alpha
\end{aligned}
$$

where $L_{n}$ and $L_{0}$ are the initial and final lengths respectively, and $\theta_{1}$ and $\theta_{2}$ are the global rotations of the nodes 1 and 2 , respectively. On the other hand, $\bar{u}, \bar{\theta}_{1}$ and $\bar{\theta}_{2}$ are the axial displacement and rotations in the local system. Finally, $\alpha$ indicates the rigid body rotation of element:

$$
\alpha=\beta-\beta_{0}
$$

where $\beta$ and $\beta_{0}$ are respectively the inclination angles of the element in the global system on final and initial configurations, respectively. The lengths of the elements may be calculated as:

$$
\begin{aligned}
& L_{0}=\sqrt{\Delta x^{2}+\Delta y^{2}} \\
& L_{n}=\sqrt{\Delta x^{\prime 2}+\Delta y^{\prime 2}}
\end{aligned}
$$

while

$$
\begin{aligned}
& \Delta x=x_{2}-x_{1} \\
& \Delta y=y_{2}-y_{1} \\
& \Delta x^{\prime}=x_{2}^{\prime}-x_{1}^{\prime}=\left(x_{2}-x_{1}\right)+\left(u_{2}-u_{1}\right) \\
& \Delta y^{\prime}=y_{2}^{\prime}-y_{1}^{\prime}=\left(y_{2}-y_{1}\right)+\left(v_{2}-v_{1}\right)
\end{aligned}
$$

An important step of the co-rotational formulation is the separation of total rotations in a rigid body rotations and deformational rotations. Starting from Equation (2), it is possible write:

$$
\begin{aligned}
& \operatorname{sen} \alpha=\operatorname{sen}\left(\beta-\beta_{0}\right)=s \cdot c_{0}-c \cdot s_{0} \\
& \cos \alpha=\cos \left(\beta-\beta_{0}\right)=c \cdot c_{0}+s \cdot s_{0}
\end{aligned}
$$

where the sines and cosines of the inclination angles of the elements are calculated as:

$c_{0}=\cos \beta_{0}=\Delta x / L_{0}$
$s_{0}=\operatorname{sen} \beta_{0}=\Delta y / L_{0}$
$c=\cos \beta=\Delta x^{\prime} / L_{n}$
$s=\operatorname{sen} \beta=\Delta y^{\prime} / L_{n}$

It should be noted that Equation (5) can evaluate the rigid body rotation of the element provided that $\alpha$ is within the range $[-\pi, \pi]$, which represents large rotations when compared to the rotations experienced by most concrete structures.

However, to determine the rigid body rotation, regardless its magnitude, it is possible update the rigid rotation every load increased by the expression:

$$
\alpha=\alpha_{a}+\Delta \alpha
$$

which $\alpha_{a}$ corresponds to the previous rigid body rotation and the rotation increment $\Delta \alpha$ is defined as:

$$
\Delta \alpha=\beta-\beta_{a}
$$

while $\beta_{a}$ is the inclination angle of the previous increment. Comparing these last two equations, the rotation increment can be obtained from Equation (5), provided that $\beta$ is replaced by $\beta_{a}$ and $\alpha$ by $\Delta \alpha$. This approach works because even when the total rigid rotation is large, since the rotation increment in each load step is generally small.

\subsection{Local-global transformation}

The analysis of the complete structure is carried out in the global system. In the co-rotational formulation, the element internal force vector and the stiffness matrix are computed in the local system and transformed to global system. This transformation will be performed using the Principle of Virtual Work (PVW). The vector of displacements on the local system is given by:

$$
\overline{\mathbf{u}}=\left[\begin{array}{lll}
\bar{u} & \overline{\theta_{1}} & \overline{\theta_{2}}
\end{array}\right]^{T}
$$

while the vector of displacements on the global system is given by:

$$
\mathbf{u}=\left[\begin{array}{llllll}
u_{1} & v_{1} & \theta_{1} & u_{2} & v_{2} & \theta_{2}
\end{array}\right]^{T}
$$


Using Equation (1), it is possible write the virtual displacements on the local system as:

$$
\delta \overline{\mathbf{u}}=\left[\begin{array}{c}
\delta \bar{u} \\
\delta \overline{\theta_{1}} \\
\delta \overline{\theta_{2}}
\end{array}\right]=\left[\begin{array}{c}
\delta L_{n} \\
\delta \theta_{1}-\delta \beta \\
\delta \theta_{2}-\delta \beta
\end{array}\right]
$$

Using Equations (3) and (4):

$$
L_{n}^{2}=\left(x_{2}^{\prime}-x_{1}^{\prime}\right)^{2}+\left(y_{2}^{\prime}-y_{1}^{\prime}\right)^{2}
$$

Thus:

$$
2 L_{n} \delta L_{n}=2 \Delta x^{\prime}\left(\delta u_{2}-\delta u_{1}\right)+2 \Delta y^{\prime}\left(\delta v_{2}-\delta v_{1}\right)
$$

Considering Equation (6), the variation of the element length can be written as:

$$
\delta L_{n}=\mathbf{r}^{T} \delta \mathbf{u} \Rightarrow \mathbf{r}^{T}=\left[\begin{array}{llllll}
-c & -s & 0 & c & s & 0
\end{array}\right]
$$

The angle $\beta$ is given from Equation (6):

$$
\operatorname{sen} \beta=\frac{\Delta y^{\prime}}{L_{n}}=\frac{\Delta y+v_{2}-v_{1}}{L_{n}}
$$

Making a variation of this expression and some algebraic manipulations:

$$
\delta \beta=\frac{\mathbf{z}^{T}}{L_{n}} \delta \mathbf{u} \Rightarrow \mathbf{z}^{T}=\left[\begin{array}{llllll}
s & -c & 0 & -s & c & 0
\end{array}\right]
$$

Finally, the transformation between global and local displacements is obtained by the substitution of Equations (14) and (16) in Equation (11). The result of this operation can be written in matrix form as:

$$
\delta \overline{\mathbf{u}}=\mathbf{T} \delta \mathbf{u}
$$

where $\mathbf{T}$ is the transformation matrix defined by:

$$
T=\left[\begin{array}{cccccc}
-c & -s & 0 & c & s & 0 \\
-s / L_{n} & c / L_{n} & 1 & s / L_{n} & -c / L_{n} & 0 \\
-S / L_{n} & c / L_{n} & 0 & s / L_{n} & -c / L_{n} & 1
\end{array}\right]
$$

According to Figure 2, the internal force vector on the local system is given by:

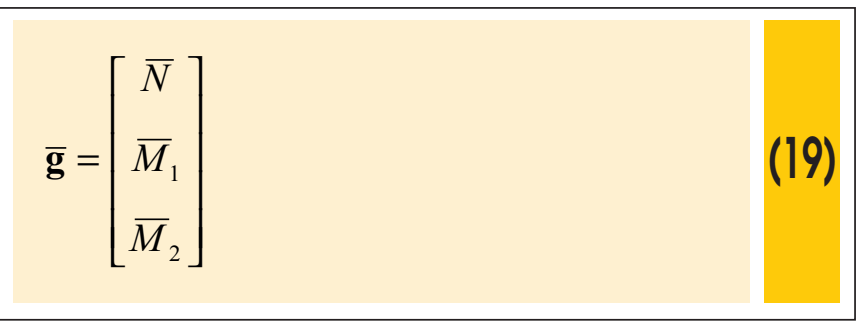

As the work is a scalar, the internal virtual work is the same in any system. Thus:

$$
\delta U=\delta \mathbf{u}^{T} \mathbf{g}=\delta \overline{\mathbf{u}}^{T} \overline{\mathbf{g}}
$$

Substituting Equation (17) in the above expression, we obtain an equation to transform the internal force vector of the element from the local system to the global system:

$\mathbf{g}=\mathbf{T}^{T} \overline{\mathbf{g}}$

The determination of the internal force vector on the global system considering the material nonlinearity will be discussed later.

The solution of the nonlinear equations of equilibrium is normally performed using the Newton-Raphson Method [2][6], which requires the use of the tangent stiffness matrix $\mathbf{K}_{t}$. This matrix relates the increment of internal forces with the displacement increment:

$d \mathbf{g}=\mathbf{K}_{t} d \mathbf{u}$

Therefore, the determination of the stiffness matrix on the global system can be performed by differentiation of Equation (21):

$$
d \mathbf{g}=\mathbf{T}^{T} d \overline{\mathbf{g}}+d \mathbf{T}^{T} \overline{\mathbf{g}}=\mathbf{K}_{e} d \mathbf{u}+\mathbf{K}_{g} d \mathbf{u}
$$

which $\mathbf{K}_{e}$ corresponds to the dependent portion of the material stiff- 
ness matrix and $\mathbf{K}_{g}$ to the geometric stiffness matrix or the initial stress matrix. Therefore, the tangent stiffness matrix is given by:

$$
\mathbf{K}_{t}=\mathbf{K}_{e}+\mathbf{K}_{g}
$$

The tangent stiffness matrix of the local system $\overline{\mathbf{K}}_{t}$ relates the increment of displacements and forces in this system:

$$
d \overline{\mathbf{g}}=\overline{\mathbf{K}}_{t} d \overline{\mathbf{u}}
$$

The determination of the stiffness matrix on global system considering the material nonlinearity will be discussed later. Using Equations (17) and (23) we obtain the expression of the matrix $\mathbf{K}_{e}$ on the global system, which is symmetrical whenever that the local stiffness matrix is symmetric:

$$
\mathbf{K}_{e}=\mathbf{T}^{T} \overline{\mathbf{K}}_{t} \mathbf{T}
$$

Finally, the geometric stiffness matrix comes from the second part of Equation (23) corresponding to the variation of the transformation matrix:

$$
\mathbf{K}_{g} d \mathbf{u}=d \mathbf{T}^{T} \overline{\mathbf{g}}=\bar{N} d \mathbf{t}_{1}+\bar{M}_{1} d \mathbf{t}_{2}+\bar{M}_{2} d \mathbf{t}_{3}
$$

where $\mathbf{t}_{k}$ indicates the column $k$ of the matrix $\mathbf{T}^{T}$. The transformation matrix defined in Equation (18) can be written as a function of vectors $\mathbf{r}$ and $\mathbf{Z}$ defined in Equations (14) and (16), respectively. Differentiating this expressions:

$$
\begin{aligned}
& d \mathbf{r}=\mathbf{z} d \beta \\
& d \mathbf{z}=-\mathbf{r} d \beta
\end{aligned}
$$

Therefore, the geometric stiffness matrix on the global system is given by

$$
\mathbf{K}_{g}=\bar{N} \frac{\mathbf{z z}^{T}}{L_{n}}+\frac{\left(\bar{M}_{1}+\bar{M}_{2}\right)}{L_{n}{ }^{2}}\left(\mathbf{r z} \mathbf{z}^{T}+\mathbf{z r}^{T}\right)
$$

It should be noted that this matrix is always symmetrical.

\subsection{Local element}

It is important emphasize that transformations between the local and global systems are independent of the type of element used on the local system, provided that the degrees of freedom and internal forces of the element are represented in Figure 2. This allows the use of different theories for the formulation of the local element, while the internal force vector and the stiffness matrix on the global system are obtained using Equations (18), (21), (24), (26) and (29).

In this paper, the local element is based on the Classical Beam Theory (Euler-Bernoulli). According to this theory, the cross sections of the beams remain plane and perpendicular to the longitudinal axis when the beams deform, since the shear strain is neglected. Using this hypothesis, it can be shown that the strain in the direction of the bar axis $\left(\varepsilon_{x}\right)$ can be written as:

$$
\varepsilon_{x}=\varepsilon_{m}-y \kappa
$$

where $\varepsilon_{m}$ is the strain in the centroid of the cross section (membrane strain), $\kappa$ is the curvature of the bar, and $y$ is the vertical distance from a given point to the centroid of the cross-section. Therefore, we can define the of generalized strain vector $(\varepsilon)$ as:

$$
\boldsymbol{\varepsilon}=\left[\begin{array}{c}
\varepsilon_{m} \\
\kappa
\end{array}\right]
$$

In the analysis of framed structures is more convenient to work with stress resultants (i.e. generalized stresses) than with the stresses directly. The normal force $N$ corresponds to the axial force in the bar:

$$
N=\int_{A} \sigma_{x} d A
$$

where $\sigma_{x}$ is the normal stress in the axial direction and $A$ is the cross-section area. The bending moment $M$ is the resultant of the moments generated by stresses around the horizontal axis of the cross-section:

$$
M=\int_{A}\left(-y \sigma_{x}\right) d A
$$

In order to simplify the notation, the stress resultants can be grouped in the vector of generalized stresses $(\sigma)$ :

$$
\boldsymbol{\sigma}=\left[\begin{array}{l}
N \\
M
\end{array}\right]
$$

The formulation of nonlinear finite elements is usually developed through the Principle of Virtual Work. In the case of the classical theory of beams: 


$$
\delta U=\int_{V} \delta \varepsilon_{x} \sigma_{x} d V=\int_{L} \delta \varepsilon^{T} \boldsymbol{\sigma} d x
$$

The formulation of this element includes the calculation of strains $(\varepsilon)$, internal forces $(\overline{\mathbf{g}})$ and tangent stiffness matrix $\left(\overline{\mathbf{K}}_{t}\right)$. The generalized strains within the element are given by:

$$
\begin{aligned}
& \varepsilon_{m}=u,{ }_{x}+\frac{1}{2} v,_{x}^{2} \\
& \kappa=v,,_{x x}
\end{aligned}
$$

where $u$ is the axial displacement and $v$ is the transversal displacement. It is important that the expression of the curvature is linear because the rotations in the local system are always small.

On the other hand, the membrane strain is nonlinear, incorporating the effect of transversal displacements through the use of the Green-Lagrange strain. Alternatively, it could be considered only the linear portion of the membrane strain, since the transversal displacements on the local system are small. However, the use of the Green-Lagrange strain on the local system makes the element more accurate.

Due to the order of the derivatives appearing in Equation (36), the axial displacement $u$ requires interpolation functions with continuity $C^{0}$ and transverse displacement $v$ requires functions with continuity $C^{1}$ [5]. Therefore, the displacements inside the element are interpolated from the local displacements using the expression:

$$
\begin{aligned}
& u=L_{2} \bar{u} \\
& v=H_{2} \overline{\theta_{1}}+H_{4} \overline{\theta_{2}}
\end{aligned}
$$

where $L_{2}$ is a linear Lagrange polynomial while $H_{2}$ and $H_{4}$ are the Hermite polynomials [5]. In the range of $0 \leq x \leq L$, these functions are defined as:

$$
\begin{aligned}
& L_{2}=\frac{x}{L} \\
& H_{2}=x-\frac{2 x^{2}}{L}+\frac{x^{3}}{L^{2}} \\
& H_{4}=-\frac{x^{2}}{L}+\frac{x^{3}}{L^{2}}
\end{aligned}
$$

In order to avoid the membrane locking due to unbalance of the axial and transverse terms [6], we use the average membrane deformation:

$$
\varepsilon_{m}=\frac{1}{L} \int_{L}\left(u,{ }_{x}+\frac{1}{2} v,,_{x}^{2}\right) d x
$$

Using Equation (37) and integrating the resulting expressions, we arrive at:

$$
\varepsilon_{m}=\frac{\bar{u}}{L}+\frac{1}{30}\left(2 \bar{\theta}_{1}^{2}-\overline{\theta_{1}} \overline{\theta_{2}}+2{\overline{\theta_{2}^{2}}}^{2}\right)
$$

Due this method, the axial deformation is constant along the element. Using Equation (1) it is verified that $\bar{u}=L_{n}-L$, therefore the first term of the axial strain corresponds to the variation of the distance between the element nodes, similarly to a truss element, while the second term represents the transverse displacement effect due to the bending of the element.

Using Equations (36), (37) and (40), we can write the generalized deformations:

$\boldsymbol{\varepsilon}=\mathbf{B} \overline{\mathbf{u}}$

where

$$
\mathbf{B}=\mathbf{B}_{0}+\frac{1}{2} \mathbf{B}_{L}
$$

while

$\mathbf{B}_{0}=\left[\begin{array}{ccc}1 / L & 0 & 0 \\ 0 & H_{2, x x} & H_{4, x x}\end{array}\right]$

and

$$
\mathbf{B}_{L}=\left[\begin{array}{ccc}
0 & 0 & 0 \\
0 & \frac{4 \bar{\theta}_{1}-\bar{\theta}_{2}}{30} & \frac{4 \bar{\theta}_{2}-\bar{\theta}_{1}}{30}
\end{array}\right]
$$

The virtual strain can be obtained by the variation of Equation (41):

$$
\delta \varepsilon=\overline{\mathbf{B}} \delta \overline{\mathbf{u}}
$$

\section{where}

$$
\overline{\mathbf{B}}=\mathbf{B}_{0}+\mathbf{B}_{L}
$$

Finally, using these equations, we can write the internal virtual work as: 


$$
\delta U=\delta \overline{\mathbf{u}}^{T} \overline{\mathbf{g}}=\int_{0}^{L} \delta \boldsymbol{\varepsilon}^{T} \boldsymbol{\sigma} d x=\delta \overline{\mathbf{u}}^{T} \int_{0}^{L} \overline{\mathbf{B}}^{T} \boldsymbol{\sigma} d x
$$

Therefore, the internal force vector is given by:

$$
\overline{\mathbf{g}}=\int_{0}^{L} \overline{\mathbf{B}}^{T} \boldsymbol{\sigma} d x
$$

The tangent stiffness matrix is obtained by differentiating the above equation with respect to nodal displacements:

$$
\overline{\mathbf{K}}_{t}=\frac{\partial \overline{\mathbf{g}}}{\partial \overline{\mathbf{u}}}=\overline{\mathbf{K}}_{e}+\overline{\mathbf{K}}_{g}
$$

The stiffness matrix $\overline{\mathbf{K}}_{e}$ is given by:

$$
\mathbf{K}_{e}=\int_{0}^{L} \overline{\mathbf{B}}^{T} \frac{\partial \boldsymbol{\sigma}}{\partial \boldsymbol{\varepsilon}} \frac{\partial \boldsymbol{\varepsilon}}{\partial \overline{\mathbf{u}}} d x
$$

This matrix can be written as:

$$
\mathbf{K}_{e}=\int_{0}^{L} \overline{\mathbf{B}}^{T} \mathbf{C}_{t} \overline{\mathbf{B}} d x
$$

where $\mathbf{C}_{t}$ is the tangent constitutive matrix that relates increments of generalized stresses and strains:

$$
\mathbf{C}_{t}=\frac{\partial \boldsymbol{\sigma}}{\partial \boldsymbol{\varepsilon}}=\left[\begin{array}{ll}
\overline{E A} & \overline{E S} \\
\overline{E S} & \overline{E I}
\end{array}\right]
$$

Differentiating the generalized strains $(N$ and $M)$ in relation to generalized deformations $\left(\mathcal{E}_{m}\right.$ and $\left.\kappa\right)$ we arrive at:

$$
\begin{aligned}
& \overline{E A}=\int_{A} E_{t} d A \\
& \overline{E S}=-\int_{A} E_{t} y d A \\
& \overline{E I}=\int_{A} E_{t} y^{2} d A
\end{aligned}
$$

which $E_{t}$ corresponds to the tangent modulus of the stress-strain curve:

$$
E_{t}=\frac{d \sigma_{x}}{d \varepsilon_{x}}
$$

Finally, the geometric stiffness matrix of the element in the local system is given by:

$$
\mathbf{K}_{g}=\int_{0}^{L} \frac{\partial \overline{\mathbf{B}}^{T}}{\partial \overline{\mathbf{u}}} \boldsymbol{\sigma} d x=\int_{0}^{L} N \frac{\partial \overline{\mathbf{B}}_{m}^{T}}{\partial \overline{\mathbf{u}}} d x+\int_{0}^{L} M \frac{\partial \mathbf{B}_{b}^{T}}{\partial \overline{\mathbf{u}}} d x
$$

where $\overline{\mathbf{B}}_{m}$ and $\overline{\mathbf{B}}_{b}$ represents the first and second row of the matrix $\overline{\mathbf{B}}$, respectively. The $\overline{\mathbf{B}}_{b}$ matrix does not depend of the displacements, so its derivative is zero. The second term is obtained by differentiating the Equations (44) and (46):

$\mathbf{A}=\frac{\partial \overline{\mathbf{B}}_{m}^{T}}{\partial \overline{\mathbf{u}}}=\left[\begin{array}{ccc}0 & 0 & 0 \\ 0 & 4 / 30 & -1 / 30 \\ 0 & -1 / 30 & 4 / 30\end{array}\right] \quad$ (56)

Since the matrix $\mathbf{A}$ is constant, the local geometric stiffness matrix can be written as:

$$
\overline{\mathbf{K}}_{g}=\mathbf{A} \int_{0}^{L} N d x
$$

\section{Material nonlinearity}

In the present work, the steel reinforcement is considered as elastic-perfectly plastic (Figure 3a), both in tension and compression. This model has only two parameters (the elastic modulus $E_{s}$ and yield strength $f_{v}$ ) and shows good agreement with experimental results.

Two stress-strain relations were adopted to represent the behavior of compressed concrete: the parabola-rectangle curve [1] (Figure $3 b)$ and the curve recommended by Eurocode 2: 2004 [7] for nonlinear analysis (Figure 3c). The equation that represents the parabolic portion of the parabola-rectangle diagram (PR) is

$$
\sigma_{c}=f_{c}\left[1-\left(1-\frac{\varepsilon_{c}}{2 \%}\right)^{2}\right]
$$

where $f_{c}$ is the compressive strength and $\varepsilon_{c}$ is the concrete strain. This expression is valid for $0 \leq \varepsilon_{c} \leq 2 \%$. The stress-strain curve for the concrete in compression given by Eurocode 2:2004 [7] (EC2) is

$$
\sigma_{c}=f_{c m}\left[\frac{k \eta-\eta^{2}}{1+(k-2) \eta}\right]
$$

where $f_{c m}$ is the compressive strength, $\eta=\varepsilon_{c} / \varepsilon_{c 1}$, where 
$\varepsilon_{c 1}$ is the strain at peak stress, $k=1.05 E_{c m} \mid \varepsilon_{c 1} / / f_{c m}$ and $E_{c m}$ is the secant modulus corresponding to $0.4 f_{c m}$ stress, as indicated in Figure 3c. Equation (59) is valid for $0<\left|\varepsilon_{c}\right|<\left|\varepsilon_{c u 1}\right|$, where $\left|\varepsilon_{c u 1}\right|=3.5 \%$. It is important to note that this curve considers the softening of concrete after the peak stress, while the parabolacurved rectangle considers a constant stress between $2 \%$ and $3.5 \%$. For both curves it is considered the concrete is completely crushed $\left(\sigma_{c}=0\right)$ for strains greater than $3.5 \%$.

The behavior of plain concrete under uniaxial tensile stresses can be represented by a bilinear curve [1], where after the first crack the concrete loses all resistance. However, in reinforced concrete, tensile stresses between cracks can be transmitted from the steel to the concrete around the steel bar by means of bond stresses between reinforcement and adjacent concrete. This effect is known as tension stiffening [17].

In this work, the tension stiffening is considered using the formula- tion presented in [10]. This formulation is based on the CEB model, developed from tests of reinforced concrete specimens subjected to uniaxial tension. In the adopted model, the tensile stresses $(s)$ in the cracked concrete are calculated by the expression:

$$
\sigma_{c t}=-\frac{\rho}{2} E_{s} \varepsilon_{c}+\sqrt{\left(\frac{\rho}{2} E_{s} \varepsilon_{c}\right)^{2}+f_{c t}^{2}(1+\eta \rho)}
$$

where $f_{c t}$ is the tensile strength of concrete, $\eta=E_{s} / E_{c}$ and $\rho$ is the effective reinforcement ratio ( $\rho=A_{s} / A_{c, e f}$ ), where $A_{c, e f}$ is the effective concrete area (i.e. the area contributing to tension stiffening). The CEB-FIP 1990 recommends using $A_{c, e f}=2.5 b(h-d)$, where $b$ is the cross-section width, $h$ is the height, and $d$ is the effective depth of reinforcement. The stress-strain relation of ten-

\section{Figure 3 - Stress-strain curves}

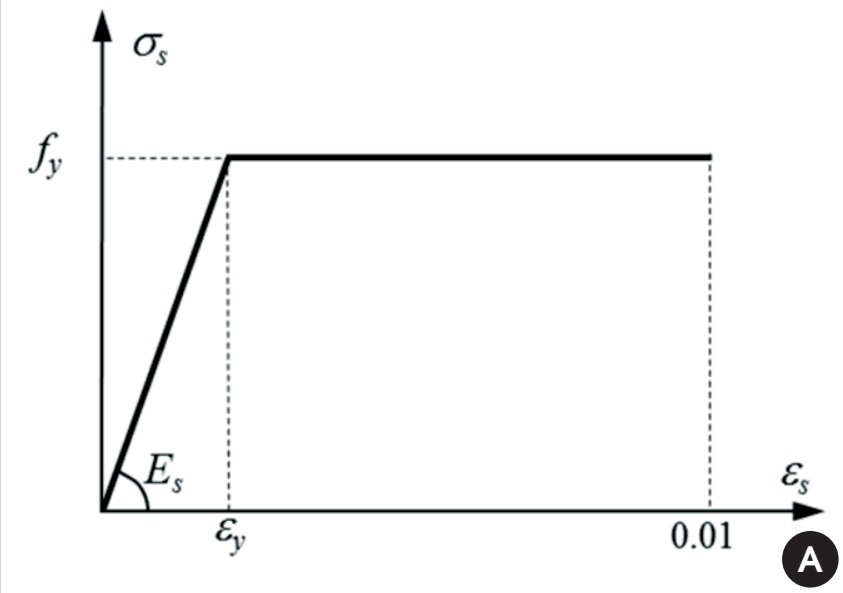

Steel

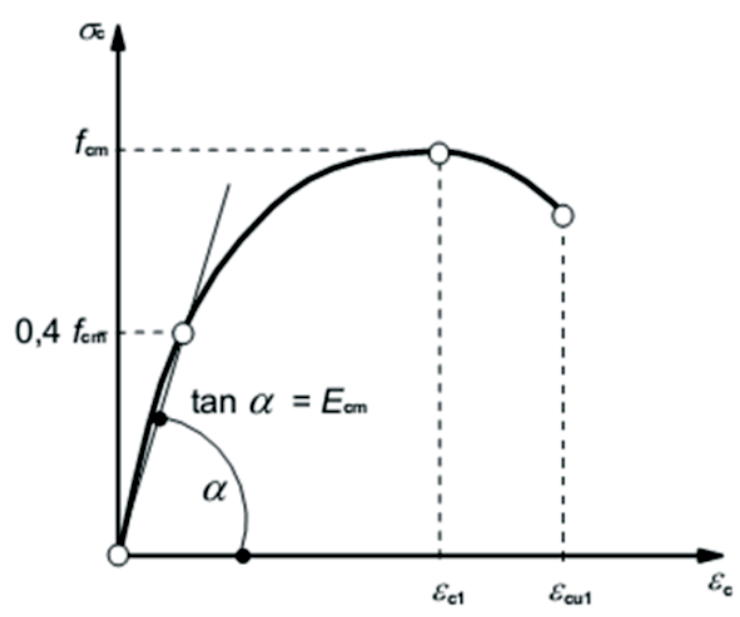

Eurocode 2 (7)

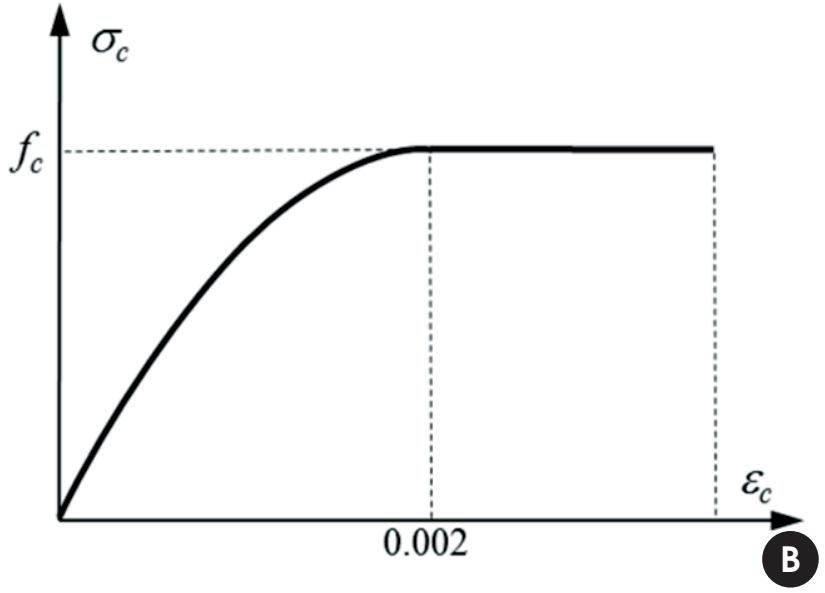

Parabola-rectangle

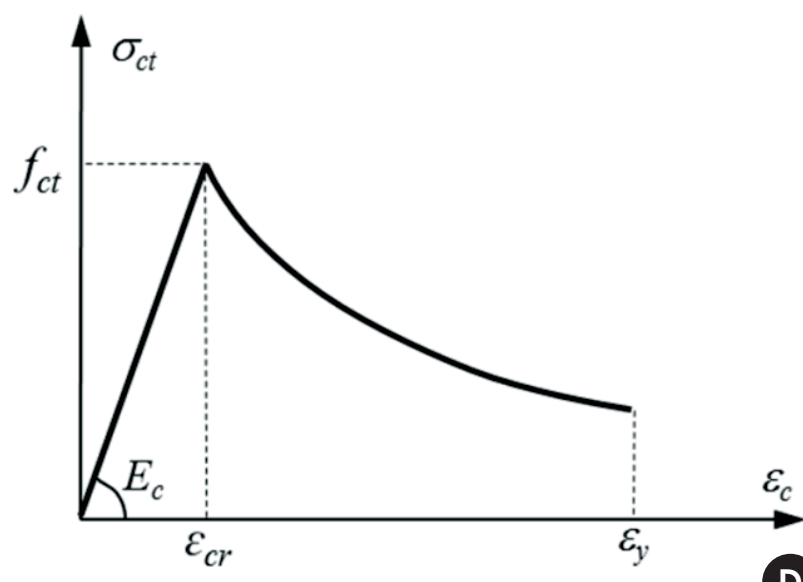

D

Concrete - tension 
sioned concrete (TS) is composed of a linear curve until cracking $\left(s_{c t}=f_{c t}\right)$ followed by a softening portion, given by Equation (60), until the yield of rebars $(e)$. This curve is illustrated in Figure $3 \mathrm{~d}$. It is important to note that the formulations presented in this paper allow the adoption of different stress-strain curves to model the behavior of steel and concrete. Thus, the stress-strain relationships described in this section and represented in Figure 3 were chosen for computer implementation due to its wide use in literature and good agreement with experimental results.

\subsection{Cross-section integration}

After the evaluation of the generalized cross-section strains $\left(\varepsilon_{p} \mathrm{e}\right.$ $\kappa)$, the stresses can be computed using the steel and concrete constitutive models. The generalized stresses $(\sigma)$ and tangent constitutive matrix (C), defined by Equations (32), (33), (34), (52) and (53), are obtained by integration of stresses and tangent modulus over the cross-section. In the case of linear elastic material these integrations are simple and can be carried out analytically. Additionally, the constituent matrix is constant, allowing the internal force vector and stiffness matrix defined by Equations (48), (51) e (57), to be integrated analytically, resulting in simple expressions in terms of generalized stresses (stress resultants) and the mechanical properties of the cross section (EA e El).

On the other hand, for piecewise nonlinear stress-strain curves, as those adopted in this work, the analytical integration is complex, difficult to implement and prone to errors due to the need for obtaining and coding various expressions specific to each curve, as carried out in [12]. An efficient implementation of this strategy for stress-strain curves defined by piecewise polynomials up to third degree was presented in [15].

Due to the complexity of analytical integration, usually the computation of stress resultants and constitutive tangent matrix is performed by numerical integration using the Gauss or Lobatto quadrature [6]. This computational approach is easy to implement, because the same procedure is used for any stress-strain curve. Additionally, these quadratures produce exact results for polynomial curves, provided that the appropriate number of integration points is used, and show rapid convergence to the exact integral when the stressstrain curve is smooth (i.e. continuously differentiable). However, the curves used to describe the behavior of concrete are usually piecewise defined functions, not being continuously differentiable. In some cases, such as occurs after rupture by tension or compression, these curves can even be discontinuous. In this case, it is necessary to use a high number of integration points for obtaining a suitable accuracy, increasing the computational cost.

Other integration technique widely used is the Fiber Method [14], also known as Layer Method for plane problems. In this method, the cross section is divided into a number of horizontal layers. In each layer, $\sigma$ e $E_{t}$ are assumed constant with the values calculated at the center of the layer. Thus, integration is carried out summing up the contribution of each layer. This method is also simple and independent of the stress-strain curve used, but requires a large number of layers for accurate results, resulting in a high computational cost.

In [4] a mixed technique was proposed, where the cross section is divided into a predefined number of thick layers of constant height, as in the Layer Method, but within each layer the integrations are performed using the Gauss quadrature. Unfortunately, in this method each layer may contain different portions of the stress-strain

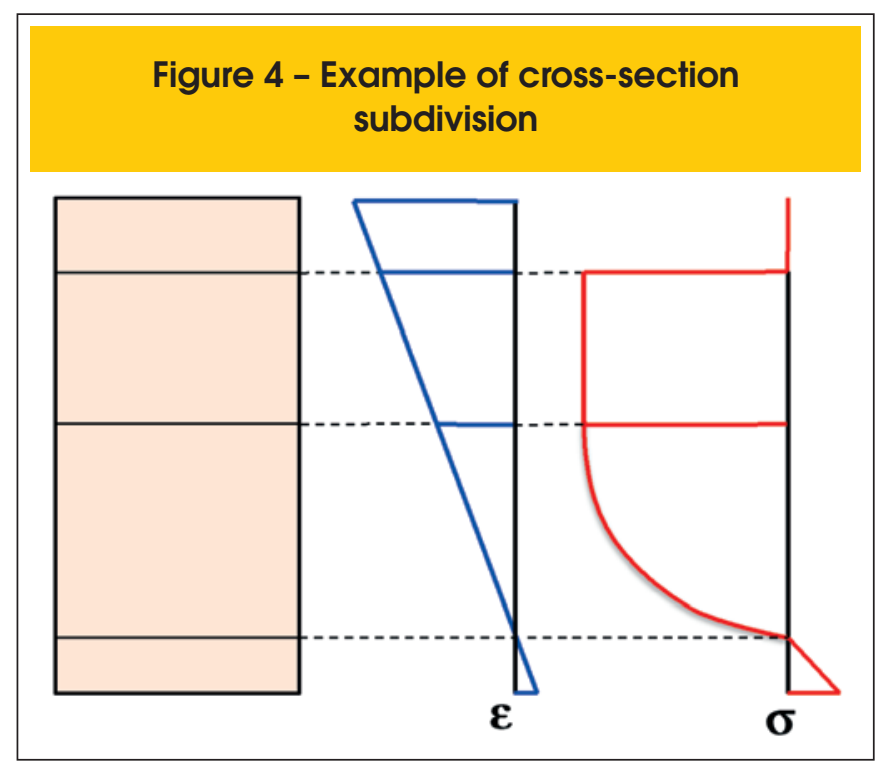

curve, causing the integrands to be not smooth. Therefore, it is necessary to use a large number of Gauss points in each layer to obtain satisfactory results.

Considering the shortcomings of the existing methods, this work proposes the ASGI (Automatic Subdivision with Gauss Integration) Method for integration of stress resultants and tangent constitutive matrix over reinforced concrete cross-sections subjected to monotonic loading and whose stress-strain curves are defined by piecewise functions. This method is computationally efficient, easy to implement, and numerically accurate. The ASGI Method is based on the subdivision of the cross section on segments of variable size whose limits are defined according to the limits of each interval of the stress-strain curve, as illustrated in Figure 4. The algorithm used for automatic subdivision of the cross-section is shown in Figure 5.

After cross section subdivision using the proposed algorithm, the stress-strain curve within each segment is continuously differentiable. Therefore, the stress resultants and constitutive tangent matrix can be integrated with high precision on each segment using the Gauss quadrature. Tables containing the parametric coordinates $\left(r_{k}\right)$ in the interval $[-1,1]$ and weights $\left(w_{k}\right)$ of Gauss points are presented in [2] and [5]. To use the Gauss quadrature, vertical coordinates $(y)$ within each segment are interpolated using the parametric coordinate $r$ :

$$
y=\frac{y_{i+1}+y_{i}}{2}+\frac{y_{i+1}-y_{i}}{2} r \Rightarrow d y=\frac{h_{i}}{2} d r
$$

where $b_{i}=y_{i+1}-y_{i}$ represents the height of each layer. In the proposed procedure, the bending moment is calculated by summing up the contribution of each segment:

$$
M=\sum_{i=1}^{n} M_{i}, \quad M_{i}=-\sum_{k=1}^{n p} w_{k} y_{k} \sigma_{k} b_{k} \frac{h_{i}}{2}
$$




\section{Figura 5 - Algoritmo de subdivisão da seção}

Given the strain limits $\left(\bar{\varepsilon}_{j}\right)$ of each interval of the stress-strain curve, the membrane strain

$\left(\varepsilon_{m}\right)$ and curvature $(\kappa)$ of the cross-section:

1) Evaluate the bottom $\left(\varepsilon_{b}\right)$ and top strains $\left(\varepsilon_{t}\right)$ using Equation (30) and the coordinates of the bottom $\left(y_{b}\right)$ and top $\left(y_{t}\right)$ of cross-section;

2) Determine the strain intervals $f_{b}$ and $f_{t}$ containing $\varepsilon_{b}$ and $\varepsilon_{t}$, respectively;

3) Evaluate the number of segments: $n=\left|f_{t}-f_{b}\right|+1$;

4) Set $y_{1}=y_{b}$ and $y_{n+1}=y_{t}$;

5) For $i=2$ to $n$ evaluate the limits of each segment:

if $\left(f_{t}>f_{b}\right) \quad j=f_{b}-2+i$

else $j=f_{b}+1-i$

$y_{i}=\left(\varepsilon_{m}-\bar{\varepsilon}_{j}\right) / \kappa$

where $n$ is the number of segments, $n p$ is the number of Gauss points in each segment, $y_{k}$ is the vertical coordinate of the Gauss point, computed substituting $r_{k}$ in Equation (61), $S_{k}$ is the stress at the Gauss point and $b_{k}$ is the corresponding cross section width at the Gauss point. The axial force and tangent constitutive matrix integrals are computed in the same way.

It is important to note that the ASGI Method based on the use of Equation (62), generate exact results when the stress-strain curves of all segments are polynomials, provided that the appropriate number of Gauss points is used. Since the maximum degree $(g)$ of the polynomial exactly integrated by Gaussian quadrature is given by $g=2 n p-1$, only one Gauss point is required for segments with constant $\sigma$ and two points for a segment where $\sigma$ is parabolic. In the case of non-polynomial curves, as Equation (59), the proposed procedure is not exact, but it generate highly accurate results even using only 3 or 4 Gauss points, as will be shown in the examples. The contribution of steel reinforcement is calculated by considering a uniform stress distribution in each rebar, since the diameter of these bars is small. Thus, the strain is evaluated the center of each bar using Equation (30) and the corresponding stress is computed using the stress-strain relationship shown in Figure 3a. Thus, the reinforcement contribution to the bending moment is calculated from:

$$
M_{s}=-\sum_{i=1}^{m} \Delta \sigma_{i} y_{i} A s_{i}
$$

where $m$ is the number of steel bars, $A s_{i}$ is the area of each bar, $y_{i}$ is the coordinate of the center of each bar and $\Delta \sigma_{i}=\sigma_{s_{i}}-\sigma_{c_{i}}$ is the difference between the steel and concrete stresses, respectively. An identical procedure is applied to the other integrals.

In the case of materially nonlinear analysis, the variation of the stress resultants and the tangent matrix along the length of the element is not explicitly known, which prevents the integrals defined in Equations (48), (51) and (57), to be computed analytically. Thus, the internal force vector and the element stiffness matrix in the local system are calculated using the Gaussian quadrature with 2 integration points with along the length of the element.

\section{Results and discussion}

The formulations described previously were evaluated by comparison of obtained results with numerical and experimental results available in the literature. Among the structures analyzed, two were chosen to be presented in this paper, in order to illustrate the behavior of reinforced concrete structures where both nonlinearities (material and geometric) are important and to study the behavior of the finite element and the integration method presented in this work. It is important to note that when the parameters of the stress-strain curves described in Section 3 were not determined experimentally, they were estimated by the expressions:

$\varepsilon_{c 1}=0.7 f_{c m}^{0.31}, \quad \varepsilon_{c u 1}=-3.5 \%, \quad E_{c m}(\mathrm{GPa})=22\left[f_{c m} / 10\right]^{0.3}$, $E_{c i}(\mathrm{GPa})=21.5\left[f_{c m} / 10\right]^{1 / 3}, f_{c t m}=0.3 f_{c k}^{2 / 3}$ and $f_{c m}=f_{c k}+8[7]$.

\subsection{Column with eccentric loading}

This column was subjected to an eccentric load until failure. Geometry, material properties, and loading [4] are shown in Figure 6. The compressive strength is $f_{c}=38.3 \mathrm{MPa}$. The following properties were used in structural analyses with the $\mathrm{EC} 2$ constitutive model: $f_{c m}=38.3 \mathrm{MPa}$ [8], $E_{c m}=33.6 \mathrm{GPa}$ [8] and $\varepsilon_{c 1}=-2.3 \%$ [4]. The tensile strength of concrete is $f_{c t}=2.9315 \mathrm{MPa}$ and $E_{c}=33.639$ $\mathrm{GPa}$. Finally, the steel properties are $f_{y}=465 \mathrm{MPa}$ [8] and $E_{s}=$ $200 \mathrm{GPa}$ [4].

The EC2 model with tension stiffening (TS) and the ASGI Method with $n p=4$ was considered initially. The Displacement Control Method was used for nonlinear analysis with increments of $-1 \mathrm{~mm}$ for the horizontal displacement of the top of the column. In order to study the effect of discretization, the column was modeled using meshes with 1, 2 and 4 


\section{Figure 6 - Column with eccentric load: geometry, material and loading (4)}
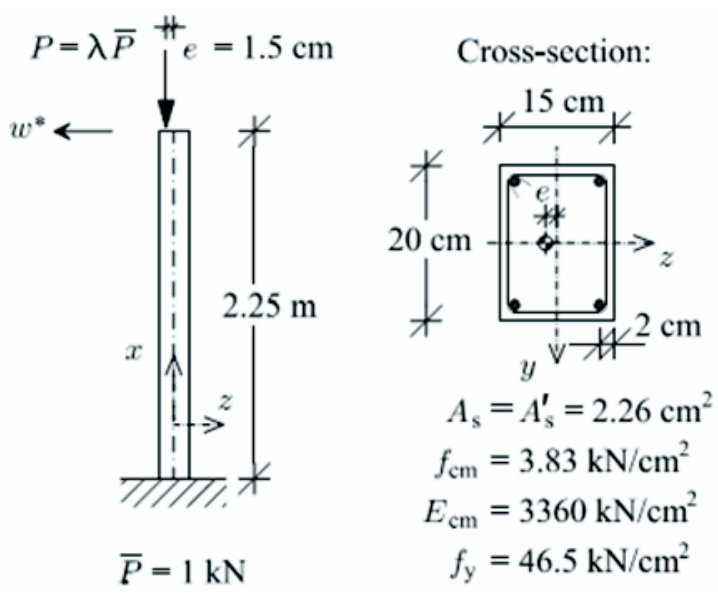

elements, obtaining the maximum loads of $457.52 \mathrm{kN}, 460.59 \mathrm{kN}$ and $460.09 \mathrm{kN}$, respectively. These results are in excellent agreement with the maximum load of $454 \mathrm{kN}$ obtained experimentally [8], showing that the proposed formulation does not require very fine meshes to adequately represent the material and geometric nonlinear behavior of the structure. It is important to note that the maximum load obtained in this work was closer to the experimental load than the maximum load $(445 \mathrm{kN})$ obtained in [4] using the EC2 model without the tension stiffening effect. It was also found that the Newton-Raphson Method presented quadratic convergence, with the number of iterations ranging between 3 and 4 throughout the analysis, even using a very tight tolerance used for convergence $\left(10^{-8}\right)$.

Next, the influence of the integration method, number of layers $(n f)$ and Gauss points $(n p)$ was assessed using a fixed number of elements (4) and constitutive model (EC2 with TS). The results obtained are shown in Table 1. These results show that the use of 20 layers generate satisfactory results. However, the ASGI Method is more accurate and efficient than the Layer Method, generating better results using just 2 Gauss points per segment than the Layer Method with 20 layers. Additionally, accurate results with six significant figures, which require the use of 600 layers, are obtained using only 3 Gauss points per segment. Note that [4] used 5 lay-

\section{Table 1 - Layer method x ASGI method}

\begin{tabular}{|cccc|}
\hline nf & $P_{\max }(k N)$ & $n p$ & $P_{\max }(k N)$ \\
\hline 10 & 457.276 & 2 & 459.673 \\
20 & 459.599 & 3 & 460.092 \\
50 & 459.991 & 4 & 460.092 \\
100 & 460.069 & 5 & 460.092 \\
600 & 460.092 & - & - \\
\hline
\end{tabular}

ers of fixed height and 10 Gauss points in each layer, showing the great advantage of using variable segments evaluated according to the proposed method.

Finally, the column was analyzed using 4 elements and crosssection integration with $n p=4$. Both EC2 and PR models with and without tension stiffening (TS) were used in the analyses. The load-displacement curves are shown in Figure 7. According to the results, the chosen constitutive models can adequately represent the structural behavior of the column. However, the EC2-TS model was the closest to the experimental results presented in [8]. The PR-TS leads to an upper bound of the load-displacement curve, while the EC2 model without TS leads to more flexible results (lower bound).

\subsection{Plane frame}

This concrete frame was tested in [9]. Geometry, cross-sections and material properties are presented in Figure 8 . The other material parameters used in the nonlinear analysis were estimated as described in Section 4. For the PR model, the compressive strength is $f=22.1 \mathrm{MPa}$, while for EC2 model: $f_{-}=22.1 \mathrm{MPa}$, $E_{c m}=27.909 \mathrm{GPa}$ and $\varepsilon_{c 1}=-1,828 \%$ [4]. The tension stiffening parameters are $f_{c}=1.760 \mathrm{MPa}$ and $E_{c}=28.005 \mathrm{GPa}$. The yield strength is $f_{v}=388,9 \mathrm{MPa}$ for columns and $f_{v}=403,4 \mathrm{MPa}$ for beams. The Young's modulus is $E_{s}=202 \mathrm{GPa}$.

Initially, the plane frame was analyzed using the EC2 model with tension stiffening (EC2-TS) and cross-section integration by the ASGI Method with $n p=4$. The Displacement Control Method was used for nonlinear analysis with increments of $-1 \mathrm{~mm}$ for the horizontal displacement of top-right node. In order to study the effect of discretization, the frame was modeled using meshes with 1, 2, 4 and 8 elements per member, obtaining maximum loads of 152.868 $\mathrm{kN}, 143.897 \mathrm{kN}, 141.555 \mathrm{kN}$ and $140.806 \mathrm{kN}$, respectively. These results are in excellent agreement with the maximum load of 141 $\mathrm{kN}$ obtained experimentally [9], showing that 4 elements per member is sufficient to adequately represent the materially and geometrically nonlinear behavior of this frame. It is interesting to note that the maximum load obtained in this work is closer to the ex-

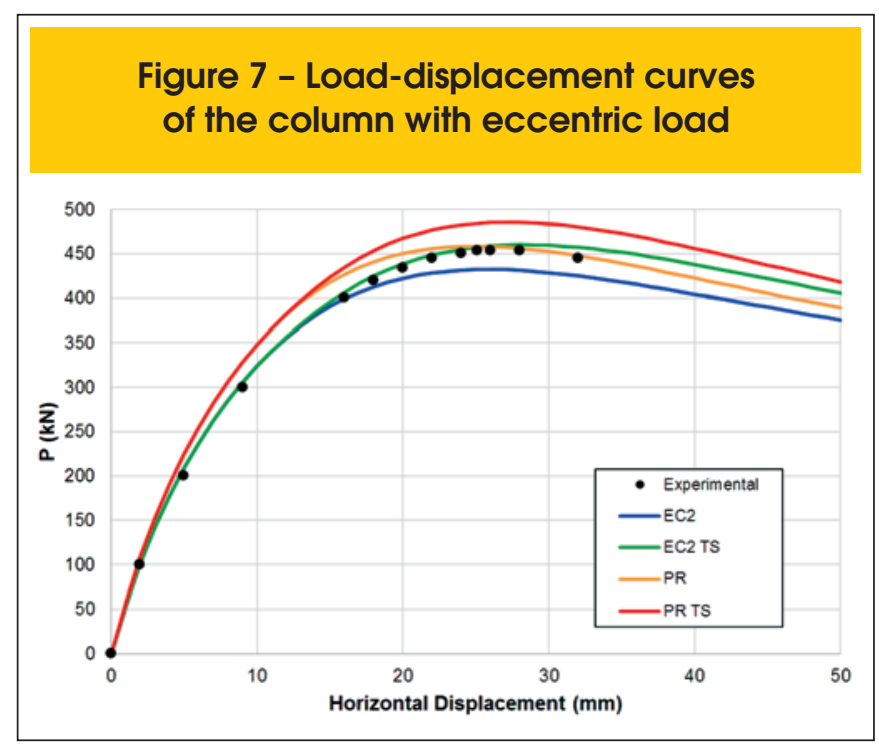




\section{Figure 8 - Concrete frame: geometry, material and loading (4)}

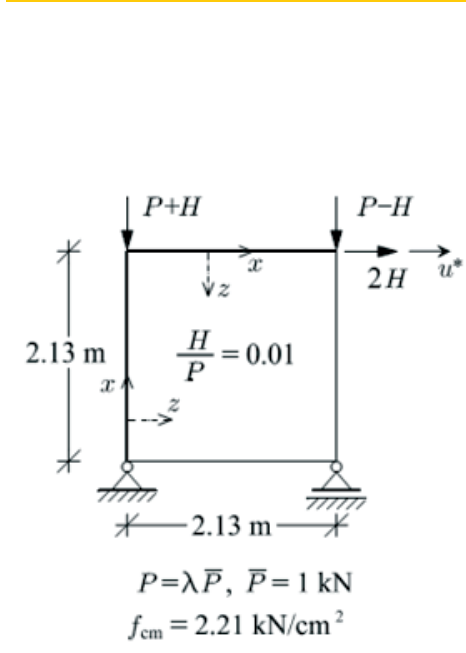

Cross-section of column:

$A_{\mathrm{s}}=A_{\mathrm{s}}^{\prime}=1.52 \mathrm{~cm}^{2}$

$f_{\mathrm{y}}=38.89 \mathrm{kN} / \mathrm{cm}^{2}$

$E_{\mathrm{s}}=20200 \mathrm{kN} / \mathrm{cm}^{2}$

Cross-section of beam:

$$
\begin{aligned}
8.1 \mathrm{~cm} & t^{2.4} \\
A_{\mathrm{s}} & =A_{\mathrm{s}}^{\prime}=5.0 \mathrm{~cm}^{2} \\
f_{\mathrm{y}} & =40.34 \mathrm{kN} / \mathrm{cm}^{2} \\
E_{\mathrm{s}} & =20200 \mathrm{kN} / \mathrm{cm}^{2}
\end{aligned}
$$

perimental value than the maximum load $(136.4 \mathrm{kN})$ obtained in [4] using the EC2 without tension stiffening. Once again, the NewtonRaphson Method presented quadratic convergence, requiring 3 to 4 iterations to convergence throughout the analysis, even using a tight convergence tolerance $\left(10^{-6}\right)$.

In this example, the cross-section integration with the Layer Method with $n f=10$ or the ASGI Method with $n p=2$ generate accurate results with 6 significant figures. However, the ASGI Method is more efficient due to the smaller number of points used in the integration. Finally, the frame was analyzed using 8 finite element per bar and cross-section integration by the ASGI Method with $n p=3$. The nonlinear analyses were carried out using the EC2 and PR models, with and without tension stiffening (TS). The load-displacement curves are shown in Figure 9. These results shown that all models can adequately represent the structural behavior of this frame. The EC2 model without TS was the one closest to the experimental results [9], but the EC2 with TS was the best with respect to the maximum load. For this structure, the EC2 with TS generate an upper bound for the load-displacement curve, while the PR model without TS leads to a lower bound. It can be noted that the initial stiffness of the models with tension stiffening (TS) is overestimated, indicating that the elasticity modulus of concrete in tension $(E)$ is lower than the value estimated using the expressions given in [7].

\section{Conclusion}

This work presented the formulation of a finite element for material and geometric nonlinear analysis of plane frames, including a new method for integration of stress resultants and tangent constitutive matrix over concrete cross-sections. The formulations and their computational implementations have been validated by comparison with experimental and numerical results available in the literature. All proposed models showed consistent results, representing adequately the behavior observed in the laboratory. However, it was found that the Eurocode 2:2004 [7] model leads to better re- sults than the parabola-rectangle model. The contribution of tension stiffening effect proved important for evaluating the ultimate load of the studied structures. However, the consideration of this effect requires a substantial number of parameters whose experimental determination is normally not performed. This leads to the use of expressions based on correlations that do not always lead to adequate results.

The integration method based on automatic subdivision of the cross section according to the sub-domains of stress-strain curves and application of Gaussian quadrature for each segment is simple, efficient and highly accurate for nonlinear analysis of concrete structures subjected to monotonic loading. Finally, the examples showed that the proposed element leads to good results using only 2 to 4 elements per member. Thus, this element is an efficient alternative for nonlinear analysis of reinforced concrete plane frames, regarding the analysis of structures with a large number of members.

\section{References}

[01] ASSOCIAÇÃO BRASILEIRA DE NORMAS TÉCNICAS. NBR 6118: Projeto de Estruturas de Concreto - Procedimentos. Rio de Janeiro, 2007.

[02] BATHE, K.J. Finite element procedures. New Jersey: Prentice Hall, 1996.

[03] BATTINI, J.M. Co-rotational beams elements in instability problems. 2002. Phd thesis - Royal Institute of Technology, Sweden.

[04] BRATINA, M.; SAJE, S.; PLANINC, I. On materially and geometrically non-linear analysis of reinforced concrete planar frames. International Journal of Solids and Structures, v.41, p.7181-7207, 2004.

[05] COOK, R.D.; MALKUS, D.S.; PLESHA, M.E. Concepts and Applications of Finite Element Analysis. 4th ed. New York: John Wiley \& Sons, 2002.

[06] CRISFIELD, M.A. Non-linear Finite Element Analysis of Solids and Structures. New York: John Wiley \& Sons, 1991. v.1.

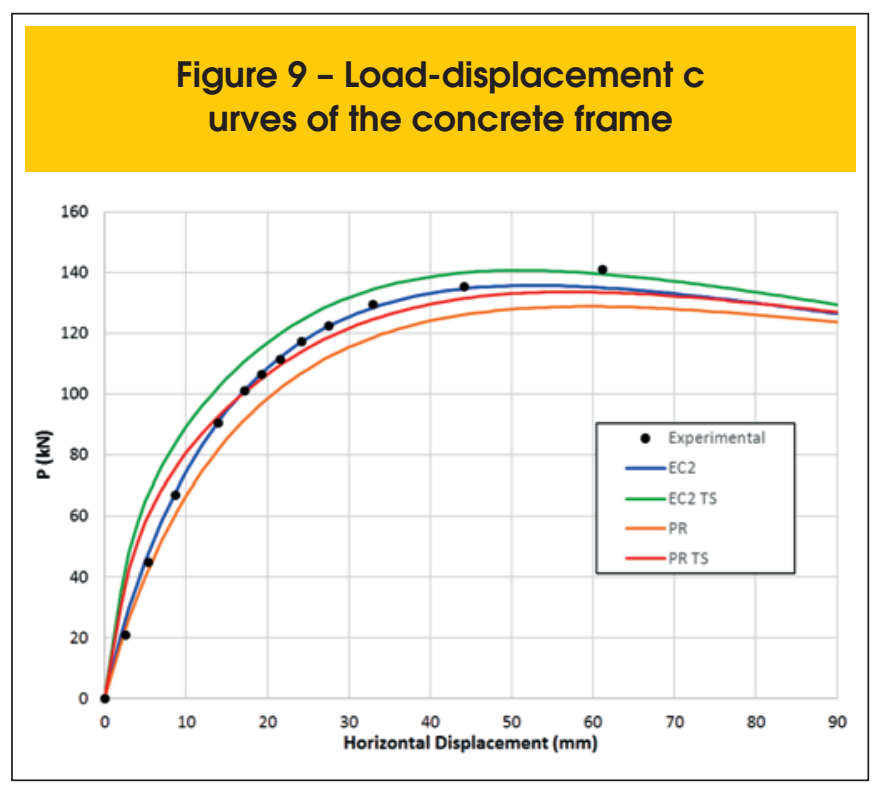


[07] EUROPEAN COMMITTEE FOR STANDARDIZATION (CEN). Eurocode 2: Design of concrete structures - Part 1-1: General rules and rules for buildings. EN 1992-1-1. Brussels, 2004.

[08] ESPION, B. Benchmark examples for creep and shrinkage analysis computer programs: creep and shrinkage of concrete. TC 114 RILEM. E\&FN Spon, 1993.

[09] FERGUSON, P.M.; BREEN, J.E. Investigation of the long concrete column in a frame subjected to lateral loads. Symposium on Reinforced Concrete Columns. American Concrete Institute SP-13, 1966.

[10] HERNÁNDEZ-MONTES, E.; CESETTI, A.; GIL-MARTÍN, L.M. Discussion of "An efficient tension-stiffening model for nonlinear analysis of reinforced concrete members", by Renata S.B. Stramandinoli, Henriette L. La Rovere, Engineering Structures, v. 48, p. 763-764, 2013.

[11] MENIN, R.C.G.; TRAUTWEIN, L.M.; BITTENCOURT, T.N. Modelos de fissuração distribuída em vigas de concreto armado pelo método dos elementos finitos. Revista IBRACON de Estruturas e Materiais, v.2, n.2, p.166-200, 2009.

[12] MELO, A. M. C. de Projeto ótimo de pórticos planos de concreto armado. 2000. Tese (Doutorado em Engenharia Civil) - Universidade Federal do Rio de Janeiro, Rio de Janeiro, 2000

[13] NANAKORN, P.; VU, L.N. A 2D field-consistent beam element for large displacement analysis using the total Lagrangian formulation. Finite Elements in Analysis and Design, v.42, p.14-15, 2006.

[14] SPACONE, E.; FILIPPOU, F.C.; TAUCER, F.F. Fibre beamcolumn model for non-linear analysis of R/C frames: Part I. Formulation. Earthquake Engineering and Structural Dynamics, v.25, p.711-725, 1996

[15] SOUSA JR., J.B.M.; MUNIZ, C.F.D.G. Analytical integration of cross section properties for numerical analysis of reinforced concrete, steel and composite frames. Engineering Structures, v. 29 p. 618-625, 2007.

[16] STRAMANDINOLI, R.S.B. Modelos de elementos finitos para análise não linear física e geométrica de vigas e pórticos planos de concreto armado. 2007. Tese (Doutorado em Engenharia Civil) - Universidade Federal de Santa Catarina, Florianópolis, 2007.

[17] STRAMANDINOLI, R.S.B.; LA ROVERE, H.L. An efficient tension-stiffening model for nonlinear analysis of reinforced concrete members, Engineering Structures, v. 30, p. 2069$2080,2008$. 